\section{Contributions from the youngest}

Corrado Campisi, ${ }^{1}$ Sara Dessalvi, ${ }^{2}$ Valentina Ferrari, ${ }^{3}$ Luca Gazzabin, ${ }^{4}$ Martina Martignon, ${ }^{5}$ Marco Pisano, ${ }^{6}$ Maurizio Pisoni, ${ }^{7}$ Simone Serantoni, ${ }^{8}$ Elodie Stasi, ${ }^{9}$ Mirko Tessari ${ }^{10}$

${ }^{1}$ Plastic, Reconstructive and Aesthetic Surgery, University of Catania, Italy; ${ }^{2}$ Digestive Surgery / Lymphatic Surgery and Microsurgery, Translational Surgery, University of Genova, Italy; ${ }^{3}$ Private Practice - Physiotherapist, Modena, Italy; ${ }^{4}$ Italian Youth Committee of the International Union of Angiology / Italian College of Phlebology / Italian Polyspecialistic Society of Young Surgeons / Compression Therapy Group / Diabetic Foot University of Naples, Italy; ${ }^{5}$ Lymphology Research Unit (Université Libre de Bruxelles); San Camillo Hospital, Treviso, Italy; ${ }^{6}$ Lymphatica Medtech SA, Ecublens, Svizzera; ${ }^{7}$ Private Practice - Physiotherapist, Savona, Italy; ${ }^{8}$ Surgery of Ulcers and Diabetic Foot, Casa di Cura Villa Fiorita, Prato, Italy; ${ }^{9} \mathrm{CMID}-\mathrm{SCU}$ Nephrology and Dialysis - Center for Interregional Coordination of Rare Disease in Piedmont and Valle D'Aosta, San Giovanni Bosco Hospital, Turin, Italy; ${ }^{10}$ Phlebology Technician, University of Ferrara, Bassi-Tessari Foundation, Ferrara, Italy

\section{The youngest point-of-view}

Thanks to the Masters of the past, lymphatic diseases have been discovered and properly studied. Learning how we have reached the present knowledge in the field of lymphology is fundamental for young lymphologists to go on with new researches. Having the opportunity to know the people, processes and contexts that have favored the birth and development of lymphology is an essential prerequisite to reflect on how to go ahead in the future. Looking at the masters of the past, starting with their accurate anatomical and physiological studies, helps to reassess and improve the bases and rationale of the treatment lymphatic diseases.

The knowledge and options of treatment of these diseases has grown remarkably in recent years. Compared to the founders, we can certainly enjoy the benefit of modern technologies and speed of sharing, being able to use remarkably different equipment and facilities. The technological tools available have helped to develop more and more mini-invasive and extremely selective procedures, but if we want to find satisfactory treatment solutions for patients with lymphedema and venous diseases, research does not only need the contribution of the clinical world (which is obviously fundamental), but also the collaboration of the (bio)engineering world.

The equipment and working methods available today allow us to create teams, including international members, capable of operating with the same passion as their predecessors, starting from their legacy but with more technological and human resources. In order to see the field of lymphology grow and to worthily continue the precious work of our masters, in the future technologies may be increasingly integrated with the knowledge made available by professionals in all fields, and combine different perspectives.

Another important aspect is that to involve patients in the management of the lymphatic diseases, making them progressively independent, compatibly with the severity of their condition, age and lifestyle. This would result in faster stabilization of chronic lymphedema, in order to offer the patient a fairly good quality of life and manage the disease by outpatient care. However, in Italy self-care or self-management in the area of circulatory and lymphatic disorders remains a controversial and unpopular subject. The future will be guided by a strict collaboration between colleagues, professionals from different fields and different views, united by a common purpose. Today patients with lymphedema are often not referred to the specialist early and this delay greatly reduces the chances of successful treatment due to the onset of fibrosis. Surgery is still wrongly considered as a treatment of last resort, even if it offers very favorable results, particularly at the earlier stages of the disease. We should not see our colleague as antagonists, but as coworkers with whom through dialogue we can identify a starting point for a discussion on complex cases and find solutions through multidisciplinary care and rehabilitation. In order to offer the patient all the currently available options for the treatment of such a complex and invalidating disease as lymphedema, the task of any young physician is to raise awareness in the operators of the sector, so that they may refer patients to specialists in time. This would create a multidisciplinary network focused
Correspondence: Sara Dessalvi, Digestive Surgery/Lymphatic Surgery and Microsurgery, Translational Surgery, University of Genova, Genova, Italy.

E-mail: saradessalvi@hotmail.it

Key words: Italian Phlebolymphology; history; Masters of the past; phlebology; lymphology.

Conflict of interests: the author declares no potential conflict of interests.

This paper is part of the monographic issue: 'Did the Masters of the past know the future? History and update of Italian Phlebolymphology' - Guest editor: Alberto Macciò (Phlebology - Part I edited by G. Agus; Phlebology - Part II edited by P. Bonadeo; Lymphology edited by F. Boccardo).

Received for publication: 30 June 2020.

Revision received: 10 July 2020.

Accepted for publication: 15 July 2020.

This work is licensed under a Creative Commons Attribution 4.0 License (by-nc 4.0).

(C) Copyright: the Author(s), 2020

Licensee PAGEPress, Italy

Veins and Lymphatics 2020; 9:9258

doi:10.4081/vl.2020.9258

on our goal: to offer patients the best possible service, built on the experience of the past and the scientific and technological discoveries of the present.

Phlebo-lymphology is getting wider and wider and the number of young people approaching it is smaller and smaller. We think the time has come for scientific societies to try to effectively motivate young researchers, and older colleagues should help the youngest ones in continuity. In their profession, as well as in all the areas of life, people feel motivated only when they are fascinated by something - and it must be something for which they are willing to work hard. This is why, in a historical context of this kind, the testimony of the Masters of the past becomes a significant legacy, but the Masters of the present day should pass on to young people, through their passion and dedication to work, that humble attitude that seems to have been lost. Scientific societies should focus their policies on young people, because they are the future. This is necessary if we want to continue in this profession and build the future history of the schools from which we come.

Young lymphologists rise a question: Are we the last of an old world or the first of a new one? 